\title{
Competitiveness In A Post Sarbanes-Oxley Economy And Its Impact On Small And Mid-Size Companies
}

Martin Samuel, Johnson \& Wales University, USA David Sabot, Johnson \& Wales University, USA

Peter DelPiano, Doctoral Candidate, Nova Southeastern University, Johnson \& Wales University, USA

\begin{abstract}
With the increase in the number of people who had a stake in the Stock market coupled with 9/11 and Enron (which created a climate of uncertainty); a need was created for more assurance in the Stock market. Sarbanes-Oxley (SOX) was created to answer the need for accuracy and reliability of financial reporting. SOX imposed unprecedented close government oversight of publicly traded companies through rigid internal control of corporate processes.
\end{abstract}

Keywords: Sarbanes-Oxley, Corporate Governance, Transparency, Scaling \& Tailoring, COSO, Competitiveness

\section{INTRODUCTION}

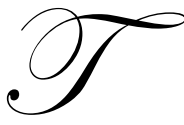

he increase in the number of Americans invested in the stock market, coupled with the accounting scandals such as Enron and WorldCom, led to the passage of Sarbanes-Oxley (SOX) in 2002. SOX imposed close government oversight of publicly traded companies.

The cost of compliance for large first tier companies turned out to be exceptionally high. With small and medium size companies now required to comply, there is concern that the competitive costs will be disastrous. A possible solution is Scaling and Tailoring. This article will examine the background and competitive aspects of Sarbanes-Oxley and will look at Scaling and Tailoring as a possible solution for the problems facing small and medium size companies and a possible standard for compliance in global markets.

\section{PROBLEM}

The first reporting tier-the large firms required to comply with the new law-has experienced a high cost of compliance. The cost of this type of compliance based on the "worst case" scenario threatens the financial viability of the small and mid-size companies. The tangible costs include extensive sustained legal and accountancy consultation and manpower costs for additional professional compliance personnel. The intangible costs include disruption of company processes through internal reorganization and refocusing on compliance objectives at the expense of business objectives. This disruption will have a commensurate adverse affect on the company's ability to compete. Can mid-level companies create shareholder value through compliance enhanced transparency? Can these companies improve competitive position and increase profitability by implementing a compliant internal control infrastructure specifically designed for that company? What is the potential effect on the U.S. economy from loss of competitive position while achieving compliance? These questions take on added significance, since there is a tremendous international interest in the United States approach to this problem. This interest is taking on special urgency since U.S. and International Accounting Standards are going through a process of harmonization. The expectation is that the process will be completed in the next year or two, resulting in the U.S. and the rest of the global community using the same set of accounting standards for compliant financial reporting. Additionally, in light of the most recent events in the global financial markets, one of the mantras to emerge from the credit meltdown is a need to increase government oversight. 


\section{BACKGROUND}

In the United States, the percentage of families that are invested in the stock market has grown tremendously. In 2001, stock ownership in the United States had increased to the point where one out of every two families had a stake in the stock market. From1962 through 2001 the percentage of families who were involved in the stock market had increased from $18 \%$ to $51.9 \%$ (Projector, 1964) (Aizcorbe, Kennickell, \& Moore, 2003).

With the increase in the number of people who were affected by the vagaries of the stock market, coupled with $9 / 11$ and the fall of Enron and the corporate dominos that went down afterward, the very stability of U.S. financial markets was threatened through a climate of uncertainty. Globally, the large U.S. corporate failures were dwarfed by the implosion of Parmalat and its fallout on the world economy. In the United States, the SarbanesOxley Act of 2002 (SOX) was fast-tracked by Congress in order to answer the need for accuracy and reliability of financial reporting. This need was addressed by mandating properly designed and effective internal control infrastructure within a company to minimize fraud. To enforce this requirement, SOX originally imposed unprecedented close government oversight of publicly traded companies in phases beginning in November of 2004 (Samuel, Sabot \& DelPiano, 2008).

\section{WILL SOX-LIKE REGULATORY REQUIREMENTS GO GLOBAL?}

There is serious international interest in the United States' approach to the need for accuracy and reliability of financial reporting. This interest is taking on special urgency since U.S. and International Accounting Standards are currently going through a process of international harmonization. The European Union (EU) and the United States have established a joint work plan for bridging differences between the U.S. and International accounting standards. (McCollum, 2006).

The plan is designed to address conflicts between the International Financial Reporting Standards (IFRS) and the Generally Accepted Accounting Principles (GAAP) required for financial reporting by publicly traded U.S. companies under SOX. The Securities and Exchange Commission (SEC) now permits foreign private issuers to submit IFRS-based reports and has announced that EU companies listed in the United States could submit IFRSbased reports beginning in 2009 (McCollum, 2006), (Parrott, 2008).

The SEC is currently considering whether to allow U.S. domestic companies a choice between GAAP and IFRS. (Parrott, 2008). In the long run, there is an even larger question. Should the SEC shed its former allegiance to GAAP and throw its weight behind international reporting standards (Turley, 2008)?

The Financial Accounting Standards Board (FASB) does not favor allowing U.S. domestic companies a choice between IFRS and GAAP. (Parrott, 2008). Robert Herz, chairman of FASB, recently suggested establishing a target date for transitioning to IFRS as the sole auditing standard for financial reporting. Likewise, the top four certified public accounting (CPA) firms prefer a shift to IFRS. Mr. Turley (2007), chairman and CEO of Ernst \& Young said that "we will weigh in with strong support for the SEC to set a certain date for a shift to IFRS".

The harmonization process between GAAP and IFRS should eventually lead to consideration of SOX-like transparency in financial reporting. Ultimately, SOX or some variant of it will probably become the global standard (Samuel, Sabot \& DelPiano, 2008).

\section{WHAT ARE THE POTENTIAL ADVERSE EFFECTS RESULTING FROM COMPLIANCE?}

So far the first tier accelerated large companies, defined as greater than $\$ 700$ million in market capitalization, (United States Government Accountability Office, 2006) reporting under SOX have been required to comply with the new requirements for financial reporting under Section 404, (the focus is not on reporting merely what the numbers are, but the emphasis is reporting on how and why those numbers were obtained) with virtually no guidance from the SEC or Congress. Consequently, these companies worked on the "worst case" scenario to achieve compliance with these new and stricter requirements. These first tier companies survived this difficult 
transition. However, this was accomplished at a tremendous cost. Other companies have chosen to avoid these requirements by going private or by initially listing outside the United States (Daks, 2006).

The cost of compliance based on the "worst case" scenario threatens the financial viability of these companies. The tangible costs include extensive sustained legal and accountancy consultation and manpower costs for additional professional compliance personnel. The intangible costs include disruption of company processes through internal reorganization and refocusing on compliance objectives at the expense of business objectives. This disruption will have a commensurate adverse affect on the company's ability to compete. Can mid-level companies create shareholder value through compliance enhanced transparency? Can these companies improve competitive position and increase profitability by implementing a compliant internal control infrastructure specifically designed for that company? What is the potential effect on the U.S. economy from loss of competitive position while achieving compliance (Samuel, Sabot \& DelPiano, 2008)?

\section{COMPETITIVENESS}

The cost for large company compliance with Sox has been very expensive. According to a survey commissioned by the top four CPA firms, Section 404 compliance costs in its initial year averaged more than $\$ 8.5$ million. In addition, related costs for proxy audit services averaged another $\$ 2$ million in the first year of implementation (CRA International, 2006). With costs of this magnitude, it is hard to imagine that the competitive position of these public U.S. companies, compared to that of non-public U.S. companies or foreign companies, could not be adversely impacted. Just imagine the effect of even smaller compliance costs on small and medium public companies. This situation poses real potential for inducing competitive financial disaster within this group of companies.

Although larger public companies decreased their spending in the second year to an average of $\$ 4.7$ million on Section 404 compliance costs and an average of $\$ 1,570,000$ on proxy audit costs, the potential outcome could still be devastating for small and medium public companies (CRA International, 2006).

The repercussions of the high cost of compliance and its effect on the competitive position of U.S. companies were not long in coming. There was a rising demand in corporate and some government sectors that SOX should be scrapped altogether. Even Alan Greenspan who gave SOX his blessing in a May 2005 address to the Wharton School of Business (Greenspan, 2005), reversed his position in November 2006 and called for its dismantling. "According to the former Fed chief, Sarbanes-Oxley regulations hamper business, discourage risktaking and drive foreign companies to shun the New York stock exchange for London (Greenspan, 2006)."

However, competition is a multi-faceted concept with many variables dependent upon the context and culture in which competitive business activity occurs. Supporters of SOX raised another variable of competition, global investor confidence. Competition in global financial markets is increasingly focusing upon financial transparency as a critical point in capturing investor interest.

In the financial markets of the United States, transparency through close government oversight evolved from the paralyzing impact of the Enron financial fraud implosion on investor confidence. Of course, investor confidence is not a concern limited only to the United States. One only needs to survey the fallout from the Parmalat disaster to understand this fact in the European context. Investor confidence and financial transparency form a simple but potent relationship that is having a far reaching and profound effect on global financial markets. Transparency has been defined as "the quantity and quality of information a company provides it's various constituents including shareholders and other capital providers, suppliers, customers, employees [and others]" (Churchwell \& Cynthia, 2003).

Many studies have examined the role of corporate governance, top management turnover, ownership structure, $\mathrm{CEO} /$ chairman duality, top executive turnover, board composition, global and industrial diversification, and types of compensation as each relates to shareholder value (Doukas and Travlos 1988), (Freund, Trahan, and Vasudevan 2007), (Doukas and Kan 2006), (Kang and Shivdasani 1995). Theories focused on in these studies have included agency, corporate multi-nationalism, internalization, synergy, managerialism and bonding. 
Studies by Charitou, Louca, and Panayides (2007), Foerster and Karolyi, (1993), and Eun and Saherwal (1993) of cross-listed companies (foreign companies also listed on U.S. exchanges) have been done to determine what benefits or costs are derived from listing on the U.S. as well as the home market. The benefits examined have included liquidity, lower cost of capital, increased trading volume, and price discovery. The additional cost considerations include: accounting, legal, and possibly additional taxes. The share price of companies prior to and after cross-listing has been measured to determine whether abnormal gains were produced.

A review of the literature indicates the significance of continued examination of foreign companies that choose to cross-list in the US despite the additional cost of compliance related to SOX. A significant body of literature exists today with cost benefit analysis of SOX, with many different conclusions. This is a result of the many variables affecting the stock market, corporate earnings and shareholder values.

Various studies have looked at different corporate governance mechanisms as it relates to firm value. Kang and Shivdasani (1995) studied Japanese firms and found a negative relationship between non-routine top executive turnover likelihood and firm performance as measured by earnings relative to other firms in the industry. Their study established that the main bank system in Japan performs an important governance function and that outside succession is more likely for firms with large shareholders.

Zhu and Small (2007) reviewed the literature looking at the concerns of financial professionals who were questioning the cost of SOX and whether or not it had a chilling effect on the cross-listings of international companies in U.S. markets. The result of their study indicated that there are several motives for cross-listing, including a desire to increase the visibility of the company, to tap into a more liquid market, to signal strength, or to follow tougher exchange requirements. This allows investors to take advantage of international diversification (Zhu and Small, 2007).

Charitou, et. al. (2007) examined the relationship between cross-listing and corporate governance for Canadian firms cross-listed on U.S. stock exchanges. The study found that cross-listed firms experience changes in their ownership structure after listing and that cross-listed firms have more independent boards and audit committees after listing compared to a matched sample of non-cross-listed companies and relative to the pre-listing period. The study was of companies cross-listed between the years 1997-2003 and statistics run for one year prior to listing and one year after being cross-listed. The authors found corporate governance does not have an impact on the decision to cross-list. However, improvements that relate to the independence of board and audit committees were only found in cross-listed firms.

Foerster and Karolyi (1993) also studied Canadian companies cross-listed on U.S. exchanges. They found expected stock returns for the overall sample significantly lower subsequent to cross-listing and that stock liquidity substantially increased when cross-listed. The stocks significantly increased 100 days prior to cross-listing and during the cross-listing period, but significantly dropped in the 100 days after cross-listing.

Another study of U.S. listed Canadian stocks was done by Eun and Sabherwal (2003). The study looked at 62 firms traded on the Toronto Stock Exchange that were cross-listed on a U.S. exchange covering a six month period in 1998. The purpose was to examine the contribution of cross-listing to price discovery. They found that prices on the Toronto exchange and U.S. exchanges were co-integrated and mutually adjusting. Price adjustments due to cross-market information flows took place on the Toronto as well as U.S. exchanges. Therefore, U.S. exchanges also contributed to price discovery.

No studies have been done with statistics completely post SOX. Therefore, the increases in reporting requirements have not been taken into consideration by previous studies.

One of the authors of this paper, Delpiano, in conjunction with Chin-Loy (Delpiano \& Chin-Loy, 2008) decided to rectify the situation somewhat by studying Canadian firms listed on the Toronto Stock Exchange (TSX) cross-listed on the New York Stock Exchange (NYSE) for the years 2005 - 2007 versus Canadian only listed firms, to examine the effect of SOX on shareholder value. The key research questions in this study were as follows: Do 
Canadian companies that become cross-listed add firm value after a three year period? Is there a difference in corporate governance between Canadian only and cross-listed Canadian stocks?

A comparison of cross-listed Canadian companies on both the Toronto Stock Exchange (TSX) and on the New York Stock Exchange (NYSE) with Canadian only listed stocks on the TSX, was made to establish if there is firm value added by such cross-listing. Board composition, net profit margin, and change in chief executive/chairman duality were also considered in this study. While one such study (Charitou, et. al. 2007) exists, this study examined a longer time period and with some different variables, and the period covered was almost completely pre SOX (1997-2003). The number of internationally cross-listed stocks in 1997 was 4,700 and this number declined to 2,300 by the end of 2002 (Karolyi, 2006).

At the time of the study there were 79 Canadian companies cross-listed on the New York Stock Exchange (NYSE) which is the dataset for this study. These firms were identified from the NYSE website. To qualify for this study a company needed to have been cross-listed from the TSX to the NYSE prior to January 2005 (the original SOX compliance date was November, 2004).

The final sample consisted of thirty-one companies. Companies eliminated from the study included those cross-listed after December 2004, ones that merged with other firms after 2004, mutual funds or trusts that do not operate a business, firms with unavailable governance data or firms that could not be matched with like businesses solely listed on the TSX. December 2004 is used as the cut-off to be able to compare three years of data (2005 2007) for these cross-listed companies, under SOX requirements, with their Canadian only listed counterparts. The companies were paired with Canadian firms listed on the TSX only. The matching was determined by industry and amount of revenue. The purpose was to determine the effect of SOX during the 2005 through 2007 period to the cross-listed firms, compared to the Canadian cross-listed firms. Governance data was retrieved from statements filed with the Security and Exchange Commission and the System for Electronic Document Analysis and Retrieval as well as corporate annual reports.

The bonding hypothesis was tested in this study. The bonding hypothesis credits premiums resulting from cross-listing to the bond that forms between stockholders and managers when non U.S. firms relent to U.S. regulations. The increased enforcement by the SEC may reduce information asymmetry between the management of the firm and its shareholders (Charitou, et. al.). Thus, it was expected that the increased reporting due to being listed on the NYSE would create value to the shareholders. The study utilized the independent $t$-test to perform analysis on the data.

The following hypotheses were proposed: Hypothesis 1: Canadian firms cross-listed on the NYSE would have boards of directors with a greater percentage of outside directors than Canadian firms solely listed on the TSX. Hypothesis 2: Canadian firms cross-listed on the NYSE would have a higher net profit margin than Canadian firms solely listed on the TSX. Hypothesis 3: Canadian firms cross-listed on the NYSE would have a lower percentage of $\mathrm{CEO} /$ Chairman Duality than those firms solely on the TSX.

The results show that the percentage of inside directors is significantly higher for TSX only listed companies. Specifically, the average of inside directors of TSX only firms ranges from 19 to $20.6 \%$, while crosslisted companies average between 11.7 and $12.4 \%$. The independent $t$-test performed showed this to be statistically significant. It was expected that cross-listed companies would have a higher net profit margin than those listed solely on the TSX. No significant difference was found from the independent t-test performed. It is noteworthy, however, that the average for the cross-listed companies increased from an average return of $9.2 \%$ in 2005 to $15.3 \%$ in 2007. The TSX only listed companies performed better than the cross-listed firms in 2005 and 2006.

Duality of the CEO/chairman was expected to be higher with TSX listed firms and this did not prove to be statistically significant from the results of the study. TSX only listed companies had $29 \%$ dual CEO/chairmen in 2005 and $23 \%$ in both 2006 and 2007. Cross-listed companies had 13\% in each of the three years.

The purpose of the study was to look at the effect of SOX on corporate governance and profitability. The results of the study show that there is a statistically significant difference in board independence between 
NYSE/TSX cross-listed companies and those firms listed only on the TSX. The bonding hypothesis, however, which credits premiums resulting from cross-listing to the bond that forms between stockholders and managers when non U.S. firms submit to U.S. regulations, cannot be confirmed.

The results of the study do not give significant credence to the thesis that the competitive value added through SOX corporate transparency in terms of investor confidence outweighs the demonstrated high competitive losses of SOX compliance for large public companies. The perception was that for small and Medium public companies SOX compliance could be a disaster. Witness the United States Government Accountability Office study (2006) "However, for smaller public companies (defined in this report as $\$ 700$ million or less in market capitalization), the cost of compliance has been disproportionately higher (as a percentage of revenues) than for large public companies, particularly with respect to the internal control reporting provisions in section 404 and related audit fees.” (p. 2). Something needed to be done (Samuel, Sabot \& DelPiano, 2008).

\section{SCALING AND TAILORING}

In the political/legislative haste to address the crisis in market confidence caused by $9 / 11$ and the Enron debacle, legislators failed to include any guidance. In addition to this lack of guidance, the legislative rush to issue a law with minimum debate resulted in a relative lack of legislative history for purposes of interpretation of the law as well as any guidance for publicly traded companies to achieve the new regulatory requirements. The lack of practical, administrative guidance caused the larger companies to engage in "trial and error" compliance at great expense of funds and manpower, distracting primary business focus to compliance instead of competition.

This unguided "trial and error" approach was weathered by the large companies, but raised serious questions about the financial and manpower abilities of the smaller companies to comply. Moreover, there were concerns whether the costs of this new regulatory compliance by middle level and small level publicly traded companies threatened their financial viability and diminished their competitive position by focusing company resources on the regulatory compliance effort. These circumstances caused the SEC to come up with an innovative solution. (KPMG, 2007). A new concept of "scaling and tailoring" internal control infrastructure was examined and implemented in 2008. "Scaling and tailoring" runs parallel with the inexorable movement toward harmonized auditing standards in global financial markets. It may well begin to pose answers to the challenge of achieving compliance and maintaining or even increasing competitive position.

Between 2005 and 2007, through intense political and business interest pressure, the SEC was forced to take a hard look at the costs of compliance and transparency for the smaller, second and third tier publicly traded companies. The SEC with its accounting oversight board, the Public Company Accounting Oversight Board (PCAOB), referring to emerging principles set out by the Committee of Sponsoring Organizations of the Treadway Commission (COSO), looked at corporate governance, internal control infrastructure and external (public) audit and produced a composite approach to compliance. This approach involved "scaling and tailoring" the internal control infrastructure through prioritized, risk based assessment of the corporate processes most likely to be vulnerable to fraud. "Scaling and tailoring" could be a silver bullet of sorts to achieve regulatory compliance in a controlled cost environment, potentially enhancing competitive position through established transparency.

The Treadway Commission was sponsored jointly by five major professional associations headquartered in the United States: the American Accounting Association (AAA), the American Institute of Certified Public Accountants (AICPA), Financial Executives International (FEI), The Institute of Internal Auditors (IIA), and the National Association of Accountants (now the Institute of Management Accountants [IMA]). Wholly independent of each of the sponsoring organizations, the Commission contained representatives from industry, public accounting, investment firms, and the New York Stock Exchange.

From the outset of SOX, the SEC received constant demands for additional guidance to achieve the levels of compliance demanded by the Act. (SEC, 2007). Unlike the first tier large companies that had no guidance from SOX or the SEC on how to achieve compliance, the SEC, as of June 27, 2007, provided "interpretive guidance" for smaller companies in the second and third tiers for achieving compliance on a flexible basis through a process termed "scaling and tailoring." (SEC, 2007). 
As part of this guidance, the SEC took great care to define its idea of effective "internal control over financial reporting" (IFCR). The SEC went to great lengths to demonstrate that effective IFCR means "reasonable assurance" and not absolute assurance. (SEC, 2007).

The SEC noted that internal controls can be defeated by both intentional and unintentional fraud. However, "it is possible to design into the process safeguards to reduce, though not eliminate, this risk." (@ 35324)

The SEC went on to explain that its Interpretive Guidance is organized around two broad principles. "The first principle is that management should evaluate whether it has implemented controls that adequately address the risk that a material misstatement of the financial statements would not be prevented or detected in a timely manner....The second principle is that management's evaluation of the evidence about the operation of its controls should be based on its assessment of risk". (@ 35325).

Both of these principles are focused upon risk involved in financial reporting. In assessing the risk of "material misstatement" in financial reporting, this new guidance allows the company to focus on identifying controls that are most likely to prevent misstatements in the context and circumstances that are unique to that company at that time. In documenting this assessment of risk and internal control, the company has the flexibility to select an adequate control to properly address the risk presented. In other words, the company has the flexibility to pick and choose controls to the exclusion of others as long as the controls put in place can be demonstrated by supporting documentation to provide reasonable assurance that financial misstatement will not occur. In short, smaller companies have the ability to satisfy SOX 404B financial reporting requirements "scaling and tailoring" internal controls to fit the unique circumstances of that company.

The emphasis of the concept of scaling and tailoring is on the company using its "experience and informed judgment" to select the right controls to provide reliable financial reporting by selectively choosing internal controls appropriate to the nature of that company. (SEC, 2007) In terms of top down risk-based evaluation of internal controls over financial reporting, literally, the company can identify those risks and controls most relevant to accurate and reliable financial reporting for that company.

This is a significant departure from the "trial and error" approach forced upon the first tier companies that necessarily required something of a shotgun, worst case approach to internal controls to provide reasonable assurances against fraudulent financial reporting. It was the "trial and error" approach that involved enormous cost and man hour-expenditures to achieve compliance.

The SEC's purpose in developing this small company guidance and change to the financial reporting rules was to insure that the smaller companies would not be hobbled in their capital formation endeavors and in their ability to compete with the larger companies. (SEC, 2007) (Samuel, Sabot \& DelPiano, 2008).

\section{CONCLUSION}

With the introduction of scaling and tailoring of internal controls on corporate processes, it may now be possible to achieve reasonable assurance that corporate performance information is transparent and reliable for investor purposes without overwhelming smaller companies in enormously costly compliance efforts to ensure that reliability. It was this regulatory compliance burden without the guidance of scaling and tailoring imposed on larger companies that threatened to diminish the competitive position of smaller companies when their turn came to comply. In light of the most recent events in the global financial markets, one of the mantras to emerge from the credit meltdown is a need to increase government oversight. Consequently, there is a great likelihood that Sarbaneslike regulatory oversight of financial reporting will be one of the main controls that will be imposed as a partial answer to the problems that are now occurring. Considering the competitive issues raised in this paper, possibly some form of scaling and tailoring will go global.

However, by interjecting the subjective element allowing companies to determine their own vulnerabilities to fraud in the financial reporting process, have administrators started down the path of dismantling the primary objectives inherent in SOX (Samuel, Sabot \& DelPiano, 2008)? 


\section{AUTHOR INFORMATION}

Martin Samuel is on the faculty of Johnson and Wales University at the Miami, Florida campus and is an adjunct lecturer at Nova Southeastern University in Fort Lauderdale, Florida. He has an M.A. in Economics from Brooklyn College, an M.S. in Taxation from the Zicklin School of Business and he is a Certified Public Accountant. He is also the owner of a Tax and financial planning firm. In addition, Martin Samuel had a twenty five year career with the Bureau of Labor Statistics as a Senior Economist/Unit Manager.

David Sabot is an Associate Professor at Johnson \& Wales University at the Miami, Florida campus and is an adjunct lecturer at Nova Southeastern University in Fort Lauderdale, Florida. He teaches courses on the legal environment of business, employment law, business premises liability and risk management. He teaches at both the undergraduate and graduate level. He has a J.D. from California Western School of Law and an LL.M. from George Washington University. He has an active interest in researching post Enron government regulation of corporations and corporate governance.

Peter DelPiano is an Associate Professor at Johnson \& Wales University at the Miami, Florida campus and is an adjunct lecturer at Nova Southeastern University in Fort Lauderdale, Florida. He teaches Finance and Accounting courses. He has an M.B.A. from Binghamton University and is a Doctoral candidate in Finance at Nova Southeastern University. Peter DelPiano is currently working on his dissertation in the doctoral program at Nova in the finance area. He also has prior experience in corporate finance and financial planning having previously worked at fortune 500 companies.

\section{REFERENCES}

1. Aizcorbe, A.M., Kennickell, A.B., \& Moore, K.B. (2003, January). Recent Changes in U.S. Family Finances: Evidence from the 1998 and 2001 Survey of Consumer Finances. Federal Reserve Bulletin, Vol. 89, p. 15.

2. Charitou, A., Louca, C., \& Panayides, S. (2007). Cross-listing, bonding hypothesis and corporate governance. Journal of Business Finance \& Accounting Vol. 34, pp. 1281-1306.

3. Churchwell \& Cynthia. (2003, May 26). Corporate Transparency Improves For Foreign Firms in U.S. Markets, Retrieved from the Harvard Business School Working Knowledge Web site: http://hbswk.hbs.edu/item/3489.html

4. $\quad$ CRA International survey. (2006, Spring). Retrieved from Web site: http://goliath.ecnext.com/coms2/gi_0199-5679856/Costs-drop-for-large-firms.html

5. Daks, M.C. (2006, August 3). Companies 'go Dark' to avoid SOX compliance. New Jersey Law Journal. Retrieved http://www.law.com/jsp/ihc/PubArticleIHC.jsp?id=1154509535896

6. DelPiano, P. \& Claudette, C. (2008, September 18). A study of the Relationship between Firm Performance and Corporate Governance on Canadian Companies Cross listed Post Sarbanes Oxley (SOX). GABER International Conference in Orlando, September 17-19, 2008.

7. Doukas, J.A. \& Kan, O.B., Does global diversification destroy firm value? Journal of International Business Studies Vol. 37, pp. 352-371.

8. Doukas, J. \& Travlos, N.G. (1988). The effect of corporate multinationalism on shareholders' wealth: evidence from international acquisitions. Journal of Finance Vol. 58, pp. 1161-1175.

9. Eun, C.S., Kolodny, R., \& Scheraga, C. (1996). Cross-border acquisitions and shareholder wealth: tests of synergy and internalization hypotheses. Journal of Banking and Finance Vol. 20, pp. 1559-1582.

10. Eun, C.S. \& Sabherwal, S. (2003). Cross-border listings and price discovery: evidence from U.S.-listed Canadian stocks. Journal of Finance Vol. 58, pp. 549-575.

11. Foerster, S.R. \& Karolyi, G.A. (1993). International listings of stock: the case of Canada and the U.S. Journal of International Business Studies Vol. 24, pp. 763-784.

12. Freund, S., Trahan, E.A., \& Vasudevan, G.A. (2007). Effects of global and industrial diversification on firm value and operating performance. Financial Management

13. Greenspan, A. (2005, May 15). Retrieved from the Federal Reserve Board Web site: http://www.federalreserve.gov/boarddocs/speeches/2005/20050515/ 
14. Greenspan, A. (2006, September 28). Retrieved from the Sox First Web site: http://www.soxfirst.com/50226711/greenspans_sox_reversal.php

15. Kang, J., \& Shivdasani, A. (1995). Firm performance, corporate governance, and top executive turnover in Japan. Journal of Financial Economics Vol. 38, pp. 29-58.

16. Karolyi, G.A. (2006). The world of cross-listings and cross-listings of the world: challenging conventional wisdom. Review of Finance Vol. 10, pp. 99-152.

17. Koehn, J.L. \& DelVecchio, S.C. (2006, May). Revisiting the Ripple effects of the Sarbanes-Oxley Act. The CPA Journal. Retrieved from: http://www.nysscpa.org/cpajournal/2006/506/essentials/p32.htm

18. KPMG. (2007, April). SEC and PCAOB Proposed Changes to Internal Control Assessments and Audits. Retrieved from Audit Committee Alert No. 0702 Web site: http://www.kpmg.com/aci/docs/aci_alert/ACI_ALERT_07-02.pdf

19. McCollum, T. (2006, October). European Union and United States Set Standards Work Plan. The Internal Auditor, Vol. 63, pp. 15-16.

20. NYSE.COM

21. Parrott, W. (2008, July/August). Differences between IFRS and U.S. GAAP. Florida CPA Today, p. 35.

22. Projector, D.S. (1964, March). Survey of Financial Characteristics of Consumers: Summary Description of 1962 Survey Results. Federal Reserve Bulletin, Vol. 51, p. 292.

23. Samuel, M., Sabot, D. \& DelPiano, P. (2008, September 18). Sarbanes-Oxley - Challenges facing mid-size and small-size companies. GABER International Conference in Orlando, September 17-19, 2008.

24. Securities and Exchange Commission. (2007, June 27). Commission Guidance Regarding Management's Report on Internal Control Over Financial Reporting Under Section 13(a) or 15(d) of the Securities Exchange Act of 1934; Final Rule.

25. Securities and Exchange Commission. (2007, June 27). Smaller Reporting Company Regulatory Relief and Simplification. Code of Federal regulation (CFR) 17 Parts 210.

26. TSX.com

27. United States Government Accountability Office. (2006, April). Report to the Committee on Small Business and Entrepreneurship, U.S. Senate. P. 2.

28. Turley. (2007, November 9). Mind the GAAP. Wall Street Journal.

29. Zhu, H., \& Small, K. (2007) Has Sarbanes-Oxley Led to a Chilling in the U.S. Cross-Listing Market? New York: Vol. 77, pp. 3; 32-38. 
NOTES 